\title{
REVERSED INTERATRIAL SHUNT FOLLOWING COMPLETE RELIEF OF PULMONARY VALVE STENOSIS
}

\author{
BY

\begin{abstract}
C. M. OAKLEY*, M. V. BRAIMBRIDGE, H. H. BENTALL, AND W. P. CLELAND
From the Departments of Medicine (Clinical Cardiology) and Surgery, Postgraduate Medical School of London, Ducane Road, London W.12
\end{abstract} \\ Received February 10, 1964
}

Persistence of a right-to-left interatrial shunt after relief of pulmonary valve stenosis is not necessarily related to the effectiveness of relief of the obstruction, but may reflect continued right ventricular dysfunction.

When operative relief of pulmonary stenosis is too long delayed the results may be disappointing (Johnson, 1959; Campbell, 1959; Brock, 1961; McIntosh and Cohen, 1963). The present communication concerns six patients who were cyanosed following pulmonary valvotomy despite a normal right ventricular pressure both at rest and on exercise, and who were among a series of 56 patients with pulmonary valve stenosis operated upon under cardio-pulmonary bypass at Hammersmith and Brompton Hospitals between 1958 and 1963. Hæmodynamic and angiocardiographic studies were performed in these patients from 8 months to 5 years after operation to determine the completeness of relief of the obstruction, the magnitude and site of venous admixture, and the right ventricular and total cardiac function.

\section{CASE REPORTS}

Patient 1. C. Wi., age 32, an electronic engineer, had been blue since birth. In 1960 , following several hæmoptyses he was found to have a left pleural effusion, and tubercle bacilli were cultured from his sputum. He was seen at Hammersmith Hospital and found to have gross cyanosis and clubbing, a quiet heart which was only slightly enlarged radiologically, a soft pulmonary ejection murmur without a thrill, and inaudible pulmonary closure (Fig. 1). The electrocardiogram indicated gross right ventricular and right atrial hypertrophy (Fig. 2), and at catheterization the right ventricular pressure was 192/0-14 mm. Hg (Fig. 3), and considerably above the systemic pressure of $116 / 72 \mathrm{~mm} . \mathrm{Hg}$; the atrial septum was crossed and Coomassie blue dye curves showed a right-to-left shunt at this level. The systemic arterial oxygen saturation was only 75 per cent at rest and fell to 60 per cent on exercise. The hæmoglobin was $21.5 \mathrm{~g} . / 100 \mathrm{ml}$. and PCV 76 per cent. A right ventricular angiocardiogram confirmed that the ventricular septum was closed and showed severe pulmonary valve stenosis.

Open pulmonary valvotomy via the pulmonary artery was performed under cardio-pulmonary bypass on July 4, 1961. Bronchial flow was torrential and the pulmonary valve orifice was only $3 \mathrm{~mm}$. in diameter. Although the valve opening was increased to a full $2 \mathrm{~cm}$. diameter, a patent foramen ovale was deliberately not closed as it was thought wise at the time to provide an alternative pathway for the systemic venous return during the immediate post-operative period in case of temporary right ventricular embarrassment before infundibular regression had taken place. The right atrium and right ventricle were both very large; the right ventricle showed uniform muscular hypertrophy, but no infundibular resection was deemed necessary and the right ventricle was not opened. At the conclusion of the operation the right ventricular pressure was $90 / 20 \mathrm{~mm} . \mathrm{Hg}$ and the systemic arterial pressure was $110 / 75 \mathrm{~mm} . \mathrm{Hg}$.

* In receipt of a grant from the British Heart Foundation. 


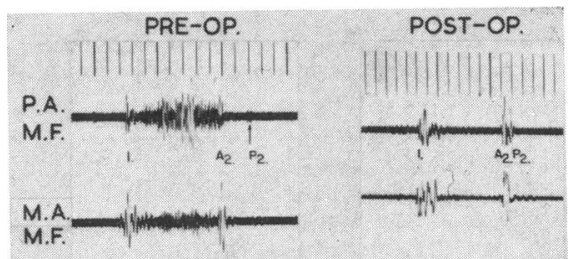

Fig. 1.-Pre- and post-operative phonocardiograms (PCG) in Patient 1 to show abolition of the obstructive murmur and the normally split second sound after valvotomy. Note also that there is no murmur of pulmonary incompetence and that there are no added sounds.

FIG. 3.-Pre- and post-operative right ventricular (RV) and right atrial (RA) pressure pulses in Patient 1 (C. Wi.). Note the distorted form of the RV trace and its high diastolic pressure, which is reflected also in the RA pulse.

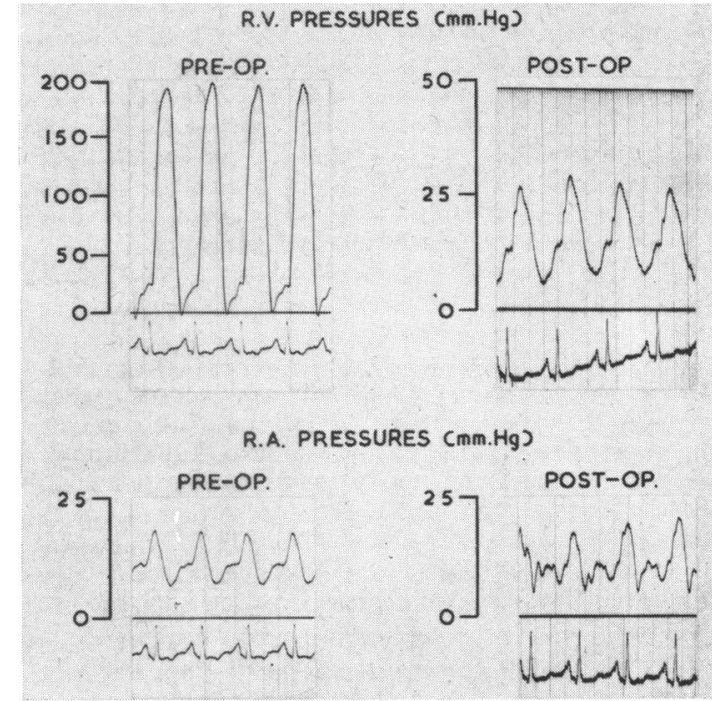

PRE-OP.

I. III. VR. V4R. V. V3. V6. $2 i-3-6 \mid$

CWi.

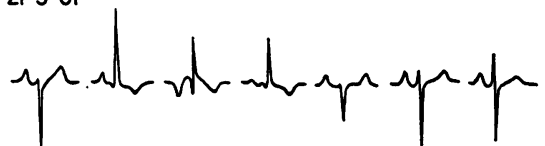
11-10-61.

R.Br.<smiles>CC(CCCCCCCCCCCC(C)(C)C)CCC(C)CCC(C)(C)CCC(C)(C)C</smiles>

R. Ri.

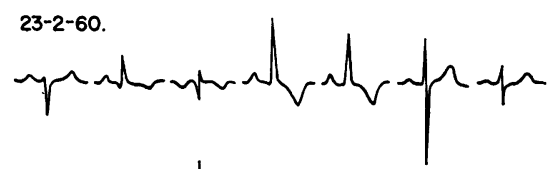

M.Li.

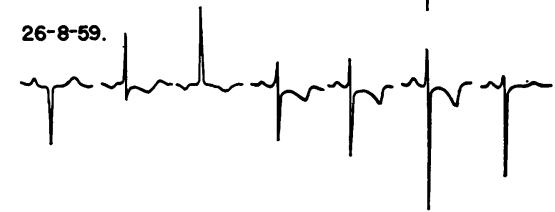

A.Wa.<smiles>CC(C)CCC(C)CCC(C)CC(C)CC(C)C(C)(C)C(C)(C)C</smiles>

POST-OP

I. III. VR. V4R. VI. V3. V6. 5-7-63.

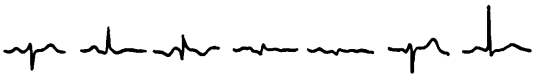

25-3-63.

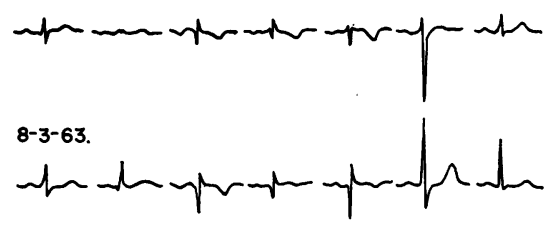

8-4-63.

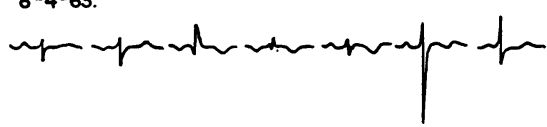

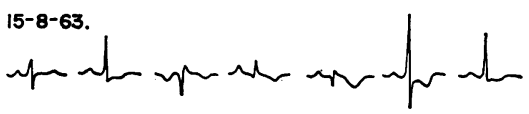

FIG. 2.-Pre- and post-operative electrocardiograms in the five patients with persistent cyanosis. The pre-operative record is in each instance mounted beside the post-operative one. In each case the post-operative electrocardiograms are nearly normal and give no hint of persisting right ventricular dysfunction. The post-operative record of A.Wa. shows ST segment depression due to digitalis. 


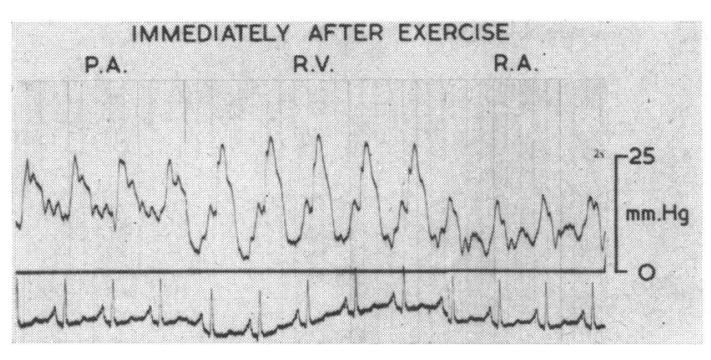

FIG. 4.-Pressure recorded on withdrawal from pulmonary artery (PA) to RA immediately after exercise in Patient 1 (C. Wi.) (some RV complexes have been cut out for compactness, but the areas shown record the maximum pressure attained in the RV).

The patient made an uneventful recovery apart from residual cyanosis, but despite relief of symptoms, dramatic improvement in general physique and gradual disappearance of the murmur, his cyanosis, clubbing, and polycythæmia did not significantly diminish. The cervical venous pressure remained at 3 to $4 \mathrm{~cm}$. with a prominent $a$ wave (Fig. 4), but there were no murmurs and no atrial or third heart sounds (Fig. 1), and the electrocardiogram two and a half years later in September 1963 showed regression of right ventricular hypertrophy (Fig. 2). The chest radiograph showed little change.

He was seen again in July 1963, two years after his operation, when the following observations were made. No pulmonary gradient was found at rest or on exercise, and even on effort the right ventricular systolic pressure remained below $30 \mathrm{~mm}$. $\mathrm{Hg}$. The right ventricular diastolic pressure of $7 \mathrm{~mm}$. $\mathrm{Hg}$ was, however, abnormally high and at end-diastole the $a$ wave peaked to $20 \mathrm{~mm}$. $\mathrm{Hg}$ (Fig. 4). The resting cardiac output was at the lower limit of normal, $2.51 . / \mathrm{min}$., and the arteriovenous oxygen difference did not widen on exercise, though this resulted in a fall in the systemic arterial saturation from 89 to 75 per cent. Coomassie blue dye curves showed a right-to-left shunt at atrial level, and the right atrial pressure was still the same as before operation (Fig. 3).

Absence of pulmonary regurgitation was confirmed by the normal pulmonary artery pulse pressure (Fig. 4), and by selective pulmonary cine-arteriography which showed no reflux of contrast from pulmonary artery into right ventricle when the opaque medium was injected into the pulmonary artery.

Comment. This man's persistent shunt through a patent foramen ovale resulted from an abnormally high right ventricular filling pressure. There was no residual pulmonary stenosis and no pulmonary regurgitation. The high right ventricular end-diastolic pressure probably reflects low compliance rather than myocardial failure, for a normal output with normal right ventricular systolic pressure even on exercise suggests that right ventricular systolic efficiency is not measurably impaired. Furthermore a ventriculotomy which might interfere with right ventricular function was not performed. Lack of compliance may reflect a massively thick ventricular muscle, and despite the electrocardiographic evidence of regression of hypertrophy perhaps operative relief took place too late to permit the right ventricle to regain normal elasticity. Surgical closure of the foramen ovale will be performed in the near future.

Patient 2. R. Br., age 32, a road sweeper, had no symptoms despite severe pulmonary stenosis with cyanosis on exertion and a hæmoglobin of $19 \mathrm{~g} . / 100 \mathrm{ml}$. The jugular pulse showed a $5 \mathrm{~cm} . a$ wave; there was a modest right ventricular heave, long pulmonary ejection murmur, and soft delayed pulmonary closure sound. Enlargement of the main pulmonary artery was seen on the chest radiograph, and the electrocardiogram revealed severe right ventricular hypertrophy. On exercise, his oxygen saturation dropped from 93 to 75 per cent. Coomassie blue dye curves showed a reversed interatrial shunt, and the resting right ventricular systolic pressure was $120 \mathrm{~mm}$. Hg.

In January 1962 open transarterial pulmonary valvotomy was performed and a fenestrated atrial septal defect was closed. No ventriculotomy was done and no infundibular muscle was resected. Despite a right ventricular systolic pressure of $110 \mathrm{~mm}$. $\mathrm{Hg}$ with a systemic arterial pressure of $100 / 75 \mathrm{~mm} . \mathrm{Hg}$ at the end of the operation, his post-operative course was uncomplicated. On discharge from hospital he still had a pulmonary ejection murmur of moderate length and intensity with a soft thrill. There was no pulmonary incompetence.

Fourteen months later he remained asymptomatic but was still polycythæmic with a hæmoglobin of $17 \cdot 2$ g. $/ 100 \mathrm{ml}$., and he was still cyanosed on exercise when his arterial saturation dropped to 78 per cent. A soft ejection murmur remained but the second heart sound was now normal, denying significant residual obstruction, and the electrocardiographic abnormality had regressed (Fig. 2). When he was studied on March 25, 1963, the right ventricular pressure was $30 / 5$ to $10 \mathrm{~mm}$. Hg at rest with an infundibular gradient of $8 \mathrm{~mm}$. $\mathrm{Hg}$ 
but no gradient across the pulmonary valve. The cardiac index was normal, $3.51 . / \mathrm{min} . / \mathrm{m} .{ }^{2}$. On exercise the gradient across the infundibulum rose to $13 \mathrm{~mm}$. $\mathrm{Hg}$ and the right ventricular pressure to $37 / 5-12 \mathrm{~mm}$. Hg. Although the mean right atrial and mean wedged pulmonary artery pressures were identical, the $a$ wave in the right atrium was $12 \mathrm{~mm} . \mathrm{Hg}$ and exceeded the $a$ wave in the indirect left atrial trace by $4 \mathrm{~mm}$. Hg. Coomassie blue dye curves localized the right-to-left shunt to atrial level. There was no left-to-right shunt. Selective right ventricular angiography showed relief of obstruction to right ventricular outflow compared with the pre-operative appearance although the ventricle remains considerably hypertrophied.

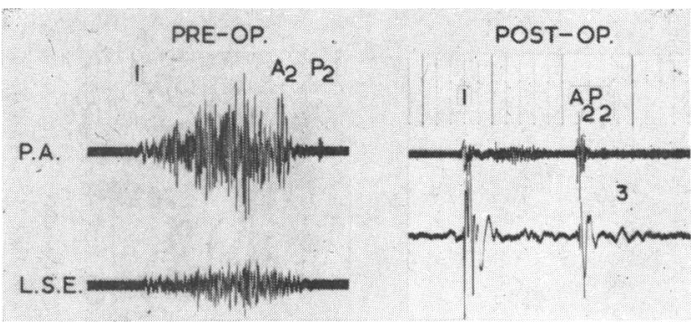

FIG. 5.-Pre- and post-operative phonocardiogram in Patient 3 (R. Ri.). The post-operative record shows an early RV third sound occurring $0 \cdot 1 \mathrm{sec}$. after aortic closure $\left(\mathbf{A}_{2}\right)$ and resembling the third sound seen in cardiac constriction.

Comment. Like the first patient, this man received operative relief late and his right ventricular diastolic function remains abnormal. Despite surgical relief of the systolic work load without ventricular incision or the production of pulmonary incompetence, the right ventricular diastolic pressure remains high and a reversed interatrial shunt has persisted. Despite its inelasticity, the systolic efficiency of the right ventricle must be good as indicated by its normal systolic pressure and output.

Patient 3. R. Ri., age 28, had pulmonary valve stenosis with cyanosis from birth and also a localized pulmonary tuberculous focus. He was considerably disabled by breathlessness, and was cyanosed and polycythæmic with a hæmoglobin of $17 \cdot 1 \mathrm{~g} . / 100 \mathrm{ml}$. A small venous $a$ wave was visible and the right ventricle was slightly prominent. A long pulmonary ejection murmur was unaccompanied by a thrill and pulmonary closure was inaudible. The right ventricular systolic pressure was $90 \mathrm{~mm}$. $\mathrm{Hg}$, well below systemic level, but on effort his arterial oxygen saturation dropped from 88 to 72 per cent.

In March 1960, a transventricular pulmonary valvotomy was performed with infundibular resection and closure of a secundum type of atrial septal defect. Operation was complicated by air embolism, and he was comatose for almost a week, but finally recovered without apparent intellectual or neurological deficit. However, he remained cyanosed, and when he left hospital a dye dilution curve and arterial samples before and during exercise showed a right-to-left shunt, with a fall in arterial oxygen saturation of 17 per cent on effort, so it seemed that the atrial defect had been incompletely closed.

He was seen again in October 1962, when he was free from symptoms and acyanotic at rest. Cardiovascular examination revealed only a very faint ejection murmur, no delay of pulmonary valve closure, and no pulmonary incompetence, but a third heart sound (Fig. 5). The chest radiograph showed no change in heart size but more normal pulmonary vascular markings. Electrocardiographic regression was complete (Fig. 2). At catheterization the right ventricular pressure was $24 / 10 \mathrm{~mm}$. $\mathrm{Hg}$. There was no pulmonary gradient, but the high right ventricular diastolic pressure rose further, and the systemic arterial oxygen saturation fell to 87 per cent on exercise. His cardiac index was low at $1.71 . / \mathrm{min} . / \mathrm{m} .{ }^{2}$.

Comment. This patient's course closely resembled that of Patient 1 in less florid form. It is of interest that before the operation the right ventricular systolic pressure was only moderately raised despite extreme stenosis of the pulmonary valve. After the operation he retained evidence of considerable impairment of right ventricular systolic efficiency as shown by the low systolic work output accomplished with a high end-diastolic pressure. The myocardium of the right ventricle might have been damaged by the potassium citrate cardiac arrest used at the time (McFarland et al., 1960), possibly also by ischæmic damage related to the air embolism (Eguchi and Bosher, 1962). The function might have been further impeded by the ventriculotomy. Now despite complete relief of pulmonary stenosis, and because the atrial defect has been incompletely closed, he maintains arterial oxygen desaturation, although with the passage of time the shunt has become substantially less than it was three weeks after operation. 


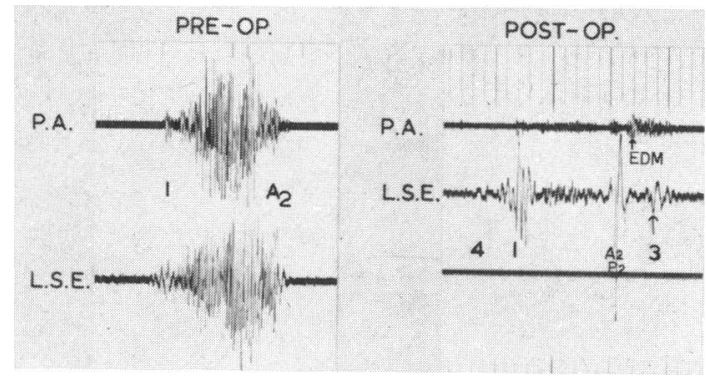

FIG. 6.-Pre- and post-operative phonocardiogram in Patient 4 (M. Li.). The post-operative record shows a loud pulmonary diastolic murmur which starts $0.04 \mathrm{sec}$. after $\mathrm{A}_{2}$. At the left sternal edge (LSE) a third sound is recorded $0.14 \mathrm{sec}$. after $\mathrm{A}_{2}$.

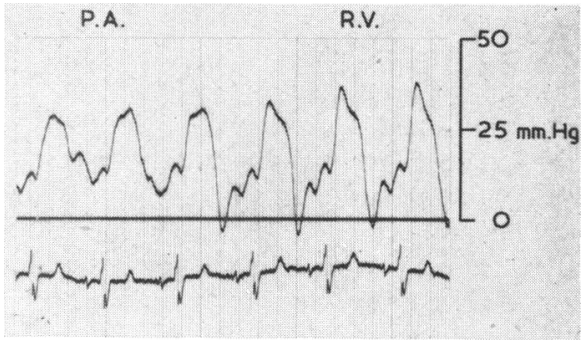

FIG. 7.-PA and RV pressure puises in Patient 4 (M. Li.). The wide pulse pressure in the PA is associated with free pulmonary valve incompetence.

Patient 4. M. Li., age 11, a schoolboy, had severe pulmonary valve stenosis with a resting right ventricular systolic pressure of $160 \mathrm{~mm}$. $\mathrm{Hg}$, but his arterial oxygen saturation was 95 per cent and did not fall on effort.

Transventricular valvotomy with infundibular resection was performed in September 1959, using potassium citrate cardiac arrest. His right ventricular pressure fell from $180 / 0$ at the beginning to $75 / 5 \mathrm{~mm}$. $\mathrm{Hg}$ at the end of the operation. Patency of the foramen ovale was not detected by digital palpation through the tricuspid valve. After operation his jugular venous pressure was raised and he had obvious pulmonary incompetence, but cyanosis was not evident.

$\mathrm{He}$ is now symptom free with minimal residual pulmonary stenosis as indicated by the soft pulmonary systolic murmur, but with free pulmonary incompetence (Fig. 6), and a slightly raised venous pressure. The present electrocardiogram suggests right ventricular volume overload with an $r^{\prime}$ SR pattern in lead V4R and slightly widened qRS, in contrast to the pre-operative pattern of severe right ventricular hypertrophy (pressure overload) (Fig. 2). At post-operative catheterization in July 1961, there was a gradient of $8 \mathrm{~mm}$. across the right ventricular outflow tract in systole, but the ventricular end-diastolic and pulmonary arterial diastolic pressures were identical (Fig. 7), and the right atrial pressure was high; pulmonary artery $32 / 12 \mathrm{~mm}$. $\mathrm{Hg}$, right ventricle $40 / 0$ to $12 \mathrm{~mm}$. $\mathrm{Hg}$, right atrium mean $10 \mathrm{~mm}$. Hg. The high cardiac index of $5.01 . / \mathrm{min} . / \mathrm{m} .{ }^{2}$ suggested normal systolic efficiency of the right ventricle and explained the excellent clinical result, although a dye dilution curve after injection of Coomassie blue dye into the right atrium showed an early appearance time due to a small right-to-left shunt, and on exercise the arterial saturation fell to 88 per cent.

Comment. This boy's right ventricular systolic pressure has fallen from 180 to $40 \mathrm{~mm}$. $\mathrm{Hg}$, but he has a ventricular scar and free pulmonary incompetence. The right ventricular filling pressure is

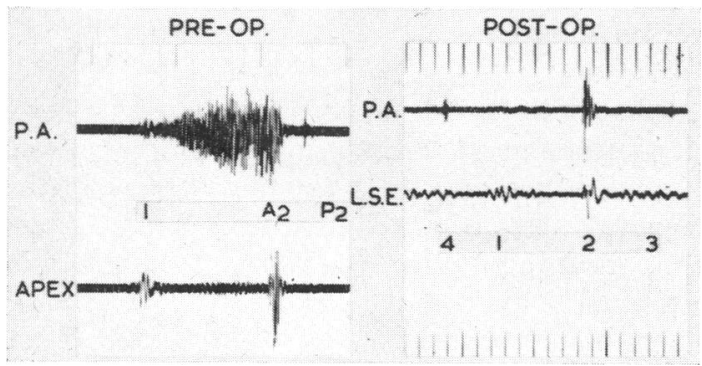

Fig. 8.-Pre- and post-operative phonocardiogram in patient 5 (A. Wa.) to show abolition of murmurs but a summated atrial and third sound in the postoperative record. actually higher than it was before operation, and there is now a small right-to-left interatrial shunt on exercise, which is of no hæmodynamic consequence, although he runs some risk of paradoxical embolism.

Patient 5. A. Wa., age 14: this girl was mentally defective and the last of 16 children, the rest of whom were healthy. She had been blue since birth, was considerably disabled, and still squatted when she became short of breath.

When first seen in December 1959, she showed cyanosis, and a physique suggestive of Marfan's syndrome. A $3 \mathrm{~cm}$. venous $a$ wave was seen in the neck, right ventricular pulsation was only slightly prominent, and the left ventricle could not be felt. 

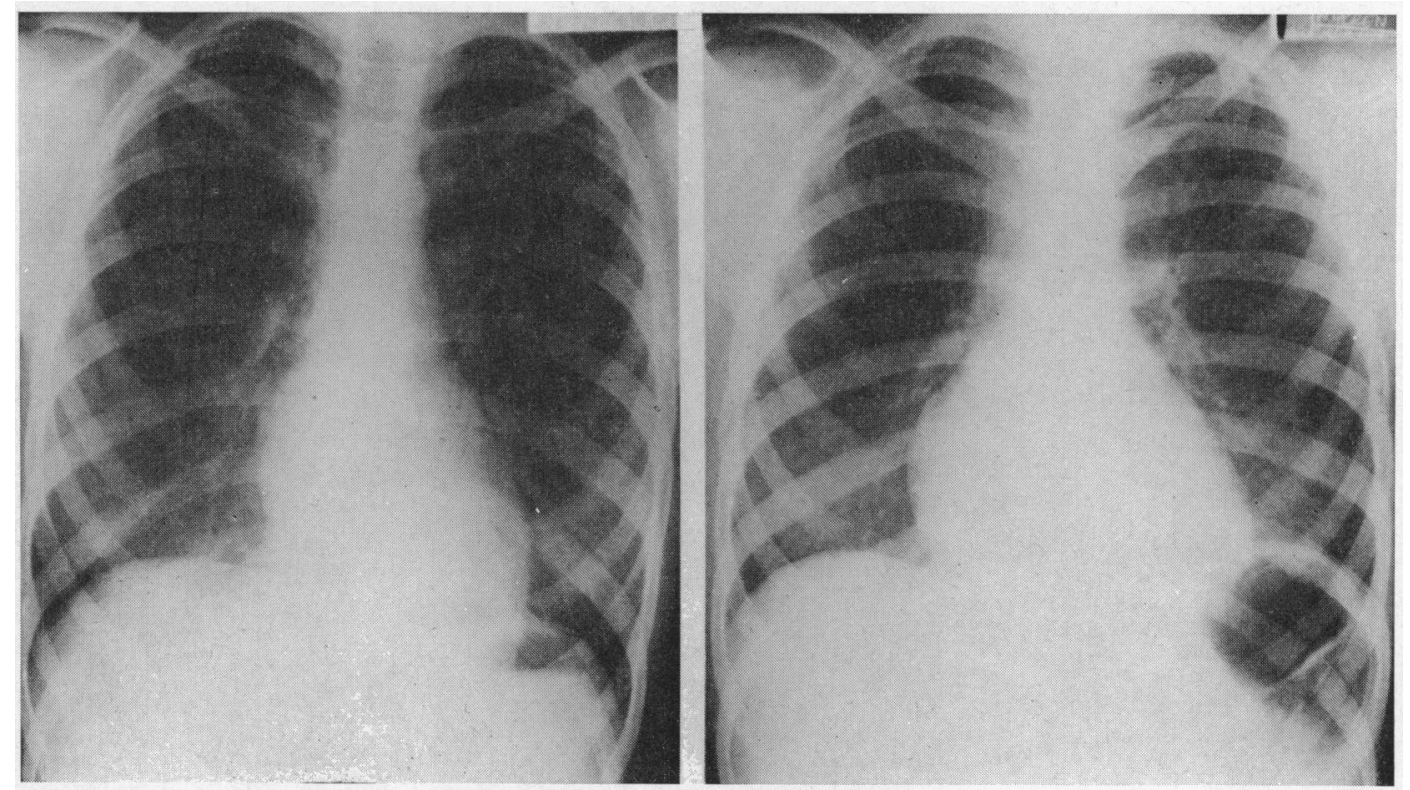

FIG. 9.-Pre- and post-operative chest radiographs in Patient 5 (A. Wa.). The pre-operative film shows a heart of normal size and configuration, but eight months after operation it has enlarged greatly and the RA is enormous. (The angiogram excluded pericardial effusion.) Note also that pulmonary blood flow appears to be largely through the dependent zones of the lung before operation whereas after operation the film shows that the upper and middle zones are better perfused.

A nearly full-length pulmonary ejection murmur was accompanied by a soft thrill, and pulmonary closure was audible but late (Fig. 8). On radiography (Fig. 9) the heart was of normal size, and no post-stenotic dilatation of the pulmonary artery could be seen, but the pulmonary vessels were notably thin in the upper and mid zones of the lung. The electrocardiogram showed considerable right ventricular hypertrophy (Fig. 2). A diagnosis of pulmonary stenosis with reversed interatrial shunt was made, and this was confirmed on selective right ventricular angiography, which revealed very marked pulmonary valvar stenosis with pulmonary arteries of small calibre and an intact ventricular septum. The right ventricular systolic pressure was $120 \mathrm{~mm}$. Hg and exactly equal to the pressure in the left ventricle, which was entered from the right side of the heart via an atrial septal defect. Her oxygen saturation dropped from 83 to 72 per cent on slight exertion.

Operation was delayed on account of intercurrent staphylococcal septicæmia with lung abscesses but no overt endocarditis. Open transarterial pulmonary valvotomy was carried out in January 1963, after which she made a full recovery without evidence of residual pulmonary damage. The pulmonary valve orifice was only $2.5 \mathrm{~mm}$., but was enlarged to $1.25 \mathrm{~cm}$., and a small high atrial septal defect was closed by two layers of running sutures. A small amount of infundibular muscle was resected by a "punch" passed into the ventricle through the valve, but the right ventricle was not opened. Before valvotomy the right ventricular pressure was $90 / 5 \mathrm{~mm}$. $\mathrm{Hg}$ and the systemic pressure was $120 / 70 \mathrm{~mm}$. $\mathrm{Hg}$. After valvotomy the right ventricular pressure was only $20 / 10 \mathrm{~mm}$. $\mathrm{Hg}$, when the systemic pressure was $100 / 70 \mathrm{~mm}$. Hg.

After operation she remained cyanosed, the venous pressure was very high, there was a constant loud third heart sound, but murmurs were entirely absent. Gross congestive failure developed and was slow to respond to treatment. Throughout her course there was never any evidence of pulmonary complications or of residual pulmonary stenosis, but three weeks after operation her resting arterial oxygen saturation was still only 84 per cent, and in February before discharge home it was 79 per cent at rest and 72 per cent on effort. Subsequently the venous pressure gradually fell and she became less cyanosed. Her mother reported that she was much improved, no longer lethargic, but very active and apparently without any disability. In August, seven months after operation, she was admitted to hospital for reassessment. She still looked cyanosed and was still polycythæmic (hæmoglogin $17 \cdot 2 \mathrm{~g}$. $/ 100 \mathrm{ml}$.). The venous pressure remained slightly raised at $4 \mathrm{~cm}$. 
TABLE

Summary of Patients

\begin{tabular}{|c|c|c|c|c|c|c|c|c|c|c|}
\hline \multirow{2}{*}{$\begin{array}{l}\text { Patient } \\
\text { No., age*, } \\
\text { and sex }\end{array}$} & \multicolumn{2}{|c|}{ Pre-operative cyanosis } & \multicolumn{2}{|c|}{ Operation } & \multirow{2}{*}{$\underset{\dagger}{\underset{\text { Final }}{\text { RVP }}}$} & \multicolumn{3}{|c|}{ Post-operative cyanosis } & \multirow{2}{*}{$\begin{array}{c}\text { Pul- } \\
\text { monary } \\
\text { incomp. }\end{array}$} & \multirow{2}{*}{$\begin{array}{l}\text { Probable } \\
\text { ætiology }\end{array}$} \\
\hline & $\begin{array}{c}\mathrm{O}_{2} \text { saturation } \\
\text { rest and } \\
\text { exercise } \\
(\%)\end{array}$ & $\underset{+}{\text { RVP }}$ & Date & Technique & & Date & $\begin{array}{c}\mathrm{O}_{2} \text { saturation } \\
\text { rest and } \\
\text { exercise } \\
(\%) \\
\end{array}$ & $\underset{(\mathrm{mm} . \mathbf{H g})}{\mathbf{R V P}}$ & & \\
\hline $132 \mathrm{M}$ & $75-60$ & 192 & $4 / 7 / 61$ & $\begin{array}{l}\text { Transarterial; } \\
\text { no infund. } \\
\text { resection }\end{array}$ & 90 & $5 / 7 / 63$ & $89-75$ & 28 & Absent & $\begin{array}{c}\text { Surgery too } \\
\text { late; "stiff } \\
\text { ventricle" }\end{array}$ \\
\hline $230 \mathrm{M}$ & $93-75$ & 120 & $16 / 1 / 62$ & $\begin{array}{l}\text { Transarterial; } \\
\text { no infund. } \\
\text { resection }\end{array}$ & 110 & $25 / 3 / 63$ & $86-78$ & 30 & Absent & $\begin{array}{l}\text { Surgery too } \\
\text { late; "stiff } \\
\text { ventricle" }\end{array}$ \\
\hline $325 \mathrm{M}$ & $88-72$ & 90 & $2 / 3 / 60$ & $\begin{array}{l}\text { Transventri- } \\
\text { cular infund. } \\
\text { resection }\end{array}$ & 85 & $\begin{array}{l}12 / 4 / 60 \\
2 / 10 / 62\end{array}$ & $\begin{array}{l}90-73 \\
94-87\end{array}$ & 24 & Absent & $\begin{array}{l}\text { Surgery late } \\
\text { but? always } \\
\text { poor R.V.; } \\
\text { continued } \\
\text { systolic and } \\
\text { diastolic } \\
\text { dysfunction }\end{array}$ \\
\hline $411 \mathrm{M}$ & $\begin{array}{l}\text { No cyanosis } \\
95-95\end{array}$ & 180 & $2 / 9 / 59$ & $\begin{array}{l}\text { Transventri- } \\
\text { cular infund. } \\
\text { resection; } \\
\text { potassium } \\
\text { citrate } \\
\text { cardiac } \\
\text { arrest }\end{array}$ & 75 & $31 / 7 / 61$ & $93-88$ & 40 & +++ & $\begin{array}{l}\text { Ventriculo- } \\
\text { tomy and } \\
\text { possible } \\
\text { effects of } \\
\text { potassium } \\
\text { citrate } \\
\text { cardiac arrest ; } \\
\text { post-opera- } \\
\text { tive pulmo- } \\
\text { nary incomp. }\end{array}$ \\
\hline 5 & $83-72$ & 120 & $24 / 1 / 63$ & $\begin{array}{l}\text { Transarterial; } \\
\text { punch } \\
\text { infund. } \\
\text { resection; } \\
\text { no ventricu- } \\
\text { lotomy }\end{array}$ & 20 & $\begin{array}{l}25 / 2 / 63 \\
13 / 8 / 63\end{array}$ & $\begin{array}{c}79-71 \\
92\end{array}$ & 20 & Absent & $\begin{array}{l}\text { ?. Always poor } \\
\text { R.V. function } \\
\text { frank con- } \\
\text { gestive failure }\end{array}$ \\
\hline 6 & $\begin{array}{l}86 \text { at rest; } \\
\text { clinical } \\
\text { cyanosis } \\
\text { and } \\
\text { clubbing }\end{array}$ & 120 & $3 / 8 / 61$ & $\begin{array}{l}\text { Transarterial; } \\
\text { no infund. } \\
\text { resection }\end{array}$ & 80 & $\begin{array}{r}4 / 8 / 61 \\
24 / 3 / 63\end{array}$ & $\begin{array}{c}73 \\
94-94\end{array}$ & 35 & Absent & $\begin{array}{l}\text { Surgery early; } \\
\text { complete } \\
\text { restoration } \\
\text { of R.V. } \\
\text { function; } \\
\text { persistent } \\
\text { foramen } \\
\text { ovale but } \\
\text { cyanosis only } \\
\text { in early } \\
\text { post-op. } \\
\text { period when } \\
\text { venous } \\
\text { pressure high }\end{array}$ \\
\hline
\end{tabular}

* Age at time of operation.

$\mathrm{RVP}=$ right ventricular systolic pressure.

$\mathrm{O}_{2}$ saturation $=$ oxygen saturation by ear oximetry. Resting saturations confirmed by arterial sampling.

$\dagger=$ pressures measured from zero point $5 \mathrm{~cm}$. below the sternal angle.

above the sternal angle, but congestive features were absent. No murmurs were audible and pulmonary closure was normal, but third and fourth sounds were present (Fig. 8). Although the electrocardiogram (Fig. 2) showed complete regression of right ventricular hypertrophy, the heart on radiography was considerably larger than it had been before operation (Fig. 9).

At cardiac catheterization the right ventricular pressure was $20 / 6 \mathrm{~mm}$. $\mathrm{Hg}$ with a pulmonary artery pressure of $18 / 8 \mathrm{~mm}$. $\mathrm{Hg}$. However, the cardiac output was only $1.71 . / \mathrm{min} . / \mathrm{m} .^{2}$, the right atrial $a$ wave was 15 $\mathrm{mm}$. $\mathrm{Hg}$, and the right atrial mean pressure $(8 \mathrm{~mm} . \mathrm{Hg})$ exceeded the indirect left atrial pressure $(6 \mathrm{~mm} . \mathrm{Hg})$. A small right-to-left interatrial shunt was confirmed by Coomassie blue dye dilution curves, although the systemic arterial saturation was now 92 per cent. She would not co-operate in exercise studies. A selective right ventricular angiogram showed no obstruction to right ventricular outflow, but the pulmonary arteries were still of very small calibre and the circulation through them was very slow. Contrast material injected through the catheter into the pulmonary artery did not flow back into the right ventricle, denying pulmonary incompetence.

Comment. The patient's severe pulmonary stenosis was completely relieved at the age of 14 . After operation she developed congestive heart failure and still has severely limited right ventricular systolic function, with a very low cardiac output. Before operation her heart had been small, but it is now considerably enlarged. Post-operative cyanosis was caused by a high right atrial pressure 
in the presence of a small residual atrial communication. The normal right ventricular systolic pressure and lack of outflow gradient indicated that the low cardiac output resulted neither from pulmonary vascular obstruction in the lungs nor residual pulmonary stenosis, but simply reflected a depressed ventricular function, despite her youth and in the absence of either ventriculotomy or post-operative pulmonary incompetence. Nevertheless the patient is symptomatically much better, presumably because of a rise in pulmonary artery perfusion pressure which improves the distribution of blood to her lungs together with the eventual rise in systemic oxygen saturation.

Patient 6. The course of this patient (S.Wi.) can be contrasted with the other patients. She had severe pulmonary valve stenosis with cyanosis and was only 2 years old when open transarterial pulmonary valvotomy was performed in August 1961. The right ventricular pressure fell from 120 at the beginning to $80 \mathrm{~mm}$. $\mathrm{Hg}$ at its completion. No infundibular resection was done, the ventricle was not opened, pulmonary incompetence was not induced, and a patent foramen ovale was not closed. After operation, the venous pressure was high and her arterial saturation on the fourth post-operative day was only 73 per cent. Though the site of venous admixture was not confirmed by indicator dye studies at that time, there was no reason to think that the cyanosis could be of pulmonary origin. Her recovery was otherwise entirely uncomplicated and she left hospital at the usual time, with a normal venous pressure and without cyanosis. The pulmonary ejection murmur was still moderately loud although shorter, and there was no pulmonary diastolic murmur.

She was seen again in March 1963. Her signs then indicated only minimal residual pulmonary stenosis without any pulmonary regurgitation, and the electrocardiogram had regressed to normal. At catheterization the maximum gradient across the right ventricular outflow tract was $10 \mathrm{~mm}$. $\mathrm{Hg}$ when the right ventricular pressure was $35 / 4 \mathrm{~mm}$. Hg. The catheter crossed the atrial septum but there was no right-to-left shunt, and the left atrial pressure exceeded the right in the normal way. Her arterial saturation was 94 per cent and did not change on effort.

Comment. Failure to close a foramen ovale was not of permanent consequence in this patient whose right ventricular filling characteristics have become normal after pulmonary valvotomy carried out in early childhood.

The salient features of these six patients are summarized in the Table.

\section{Discussion}

In pulmonary stenosis without ventricular septal defect, the right ventricle has worked against a pressure load since birth. In severe cases it is as thick or thicker than the left ventricle, and, in addition, its muscle tends to become fibrotic (Allanby and Campbell, 1949) in contrast to the healthier myocardium of patients with the tetralogy of Fallot.

Decreased distensibility is reflected by increased force of atrial contraction and by a high filling pressure, particularly when rapid stretch is required by the tachycardia and increased stroke output of exercise.

Following relief of pulmonary stenosis, the right ventricular systolic pressure may fall quickly, but the hypertrophy takes time to regress, and the right ventricle may never become as compliant as normal. It follows, therefore, that after operation the right atrial pressure will not necessarily remain below that in the left atrium during all phases of the cardiac cycle both at rest and on exercise as in the healthy subject. As interatrial shunting depends entirely on the relative filling pressure of the two ventricles and has nothing directly to do with the pressures that they exert in systole the need to close a foramen ovale is clear.

In patients C. Wi., R. Br., and M. Li. a purely diastolic dysfunction was demonstrated, in which persistant impairment of distensibility of the right ventricle continued to be met by a raised filling pressure, but the normal cardiac output both at rest and on exercise suggested that systolic function was unimpaired. In $\mathrm{M}$. Li. post-operative pulmonary regurgitation probably contributed to the high right ventricular diastolic pressure.

In our other two patients, R. Ri. and A. Wa., serious impairment of right ventricular systolic 
function was associated with a high venous filling pressure as in heart failure. Despite normal right ventricular systolic pressures and absence of residual obstruction to outflow the poor systolic work level attained was evidence of impaired right ventricular contractility. It is of interest that both these patients had been severely cyanosed since birth with right ventricular systolic pressures of only 90 and $120 \mathrm{~mm}$. $\mathrm{Hg}$, which rather suggests that the work potential of these right ventricles had always been subnormal, though hardly deserving the designation hypoplastic.

In four of our patients, the post-operative hæmodynamic pattern can be likened to that in constrictive pericarditis, a right ventricular restriction limiting diastolic filling in three, but with systolic impairment also in one. In the fifth patient the pattern was that of frank congestive failure with ventricular dilatation.

\section{SUMMARY}

Reversed interatrial shunt following complete relief of pulmonary valve stenosis has been described in six patients. One of these had not been cyanosed before his operation.

In four, one or more recognizable factors prevented or delayed restoration of normal right ventricular function after operation. Three of the patients were not operated upon until adult life and in the youngest patient the effects of ventriculotomy, potassium citrate cardiac arrest, and postoperative pulmonary incompetence were additional adverse factors. In two patients right ventricular disablement could have been suspected before operation from the combination of a relatively modest right ventricular systolic pressure with cyanosis, and after operation these two patients showed persisting systolic dysfunction in contrast to three other patients in whom only diastolic impairment of right ventricular function was evident. By contrast a sixth patient was described whose cyanosis was a transient post-operative phenomenon despite a persistent foramen ovale and who exemplified the return to normal right ventricular function which can be expected when pulmonary valvotomy for severe stenosis is performed sufficiently early in life.

Even a small right-to-left shunt must carry a substantial risk of paradoxical embolism when present over a lifetime, and secondary polycythæmia may add thrombotic hazards also.

Although persistent cyanosis indicated their right ventricular dysfunction, the outcome of surgery in these six patients is in contrast to the excellent long-term results in the other patients operated upon. It is important that an operation should be performed early in life and that the patent foramen ovale should be sought routinely and closed in order to avoid the complication of postoperative cyanosis occurring in those patients whose right ventricular function remains compromised despite complete relief of pulmonary stenosis.

We would like to thank Professor J. F. Goodwin for his very helpful criticism, Mrs. P. Smy and the Photographic Department for the illustrations, and Mrs. A. Cartwright for typing the manuscript.

\section{REFERENCES}

Allanby, K. D., and Campbell, M. (1949). Congenital pulmonary stenosis with closed ventricular septum. Guy's Hosp. Rep., 98, 18.

Brock, R. (1961). The surgical treatment of pulmonary stenosis. Brit. Heart J., 23, 337.'

Campbell, M. (1959). Valvulotomy as a curative operation for simple pulmonary stenosis. Brit. Heart J., 21, 415. Eguchi, S., and Bosher, L. H., Jr. (1962). Myocardial dysfunction resulting from coronary air embolism. Surgery,
51, 103. Johnson, A. M. (1959). Hypertrophic infundibular stenosis complicating simple pulmonary valve stenosis. Brit.
Heart J., 21, 429.

McFarland, J. A., Thomas, L. B., Gilbert, J. W., and Morrow, A. G. (1960). Myocardial necrosis following elective cardiac arrest induced with potassium citrate. J. thorac. cardiovasc. Surg., 40, 200.

McIntosh, H. D., and Cohen, A. I. (1963). Pulmonary stenosis: the importance of the myocardial factor in determining the clinical course and surgical results. Amer. Heart J., 65, 715. 